\title{
Entrepreneurial Orientation and Company Performance: Can the Academic Literature Guide Managers?
}

\author{
Sandra Schillo
}

\begin{abstract}
"Innovation is the specific tool of entrepreneurs, the means by which" they exploit change as an opportunity for a different business or a different service. It is capable of being presented as a discipline, capable of being learned, capable of being practiced. Entrepreneurs need to search purposefully for the sources of innovation, the changes and their symptoms that indicate opportunities for successful innovation. And they need to know and to apply the principles of successful innovation.
\end{abstract}

Peter Drucker (1909-2005)

Author and Management Consultant

\begin{abstract}
This article comments on the management implications of the various approaches to measuring entrepreneurial orientation (EO), and it discusses the implications of a range of empirical findings for management decisions. On the whole, the argument is that academic research needs to increase its understanding of the differences in empirical results between different studies. To date, the research mostly spells a small number of useful warnings, for example that the positive impact of EO may level off or turn negative beyond a certain point and that it may not have the anticipated positive effect in all circumstances. However, the academic research has yet to identify these circumstances to a level of specificity that could provide useful guidance to managers.
\end{abstract}

\section{Introduction}

Peter Drucker's quotation above highlights the close relation between innovation and entrepreneurship. It also suggests that much can be learned about innovation and entrepreneurship and that systematic application of this knowledge can lead to success. Academics seem to agree with Drucker, as evidenced by the vast numbers of papers published each month on innovation and entrepreneurship. Numerous researchers have published work identifying entrepreneurial companies and determining how the characteristics of such companies are linked to company performance.

In an ideal world, this knowledge about entrepreneurship and innovation would also serve to inform management practice. In reality, there are certain characteristics of the academic research that make it quite difficult to apply the research findings to manage- ment practice in the area of innovation and entrepreneurship. This article highlights these difficulties using the example of "entrepreneurial orientation" (EO).

In the academic literature, EO refers to the extent to which a firm is entrepreneurial. This concept seems particularly suited for the discussion of the applicability of academic research results to management practice because there is a strong stream of research that has used relatively consistent definitions of the concept. This research has developed since the 1980s, not only measuring $\mathrm{EO}$ in companies, but also investigating its link with company performance from many angles.

This article takes a critical view of this literature from the perspective of its implications for management. To this end, the following section outlines the definition of entrepreneurial orientation, followed by a discussion of the implications of various measurement approaches. 


\section{Entrepreneurial Orientation and Company Performance}

\section{Sandra Schillo}

Key results from the literature are then presented and discussed in terms of their implications for management, all of which are summarized in the conclusions section.

\section{Defining Entrepreneurial Orientation}

The most widely used definition of EO is based on work by Miller (1983; http://tinyurl.com/6g7r9vv), developed further by Covin and Slevin (1989; http://tinyurl.com/6drqgjk) and many others, and augmented by Lumpkin and Dess (1996; http://tinyurl.com/5t4d38y). This conceptualization has been used in over 200 studies focusing not only on entrepreneurship, but ranging from management and marketing to healthcare (George and Marino, 2011; http://tinyurl.com/6y2l3ux). The five components of EO in this stream of research are:

1. Risk-taking was historically a key characteristic associated with entrepreneurship. It originally referred to the risks individuals take by working for themselves rather than being employed, but has since been widely applied to companies, for example, when managers make decisions that commit large amounts of resources to projects with uncertain outcomes.

2. Proactiveness describes the characteristic of entrepreneurial actions to anticipate future opportunities, both in terms of products or technologies and in terms of markets and consumer demand. This characteristic was at the centre of early economic thinking in this field: the entrepreneur was thought of as someone who identifies opportunities in the marketplace and proactively pursues them (Lumpkin and Dess, 1996). Translated to the level of the firm, proactive companies are leaders in the market, rather than followers.

3. Innovativeness relates to the types of products and services a company has introduced to the market. For some theorists, innovativeness is intrinsically linked to entrepreneurship in that entrepreneurs create new combinations of resources by the very fact of their entry into the market. In the context of EO, innovativeness is defined more narrowly, emphasizing the importance of technological leadership to the company, as well as changes in its product lines.

4. Competitive aggressiveness refers to the company's way of engaging with its competitors, distinguishing between companies that shy away from direct competition with other companies and those that aggressively pursue their competitors' target markets.
5. Autonomy "refers to the independent action of an individual or a team in bringing forth an idea or a vision and carrying it through to completion" (Lumpkin and Dess, 1996) without being held back by overly stringent organizational constraints. Although this component seems to primarily have "face validity" in the context of large organizations, many researchers have applied it to the context of small companies and obtained statistically significant findings.

The components have typically been measured using questionnaire items with Likert-type scales (i.e. from 15 or 1-7), as shown in Table 1. Some researchers have anchored the items of both sides of the scale (i.e., they provided explanations of both the 1 and the 7), while others have only provided a single statement to be ranked (e.g., as shown in Table 1). There is some evidence (Miller, 2011; http://tinyurl.com/6jjzdkx) that suggests that the scale remains robust even with slight variations in the wording of questions or other minor measurement variations.

\section{Management Implications of Construct Measurement}

Authors vary in how they combine the dimensions above into the overall EO construct. In contrast to the above-mentioned variations in the wording of the items, the variations in the combination of the different components has notable implications when trying to apply the concepts in the context of corporate management. The most common variations are for researchers to use either the three components of risk-taking, proactiveness, and innovativeness (Miller, 1983; Covin and Slevin, 1989) or all five components. There are also studies that report on single components only. In addition, a small number of studies use practically any other combinations of the components.

In terms of management implications, the studies using single components are straightforward - the component labels are reasonably intuitive and typically can be translated relatively easily into management practice. The interpretation of the combinations of the components into an overall EO construct, however, requires more attention to the details of how the construct is formed.

Some authors suggest that each of the dimensions is a reflection of a company's EO. In other words, if they could be measured perfectly, each dimension would have the same score as the overall EO construct. This 


\section{Entrepreneurial Orientation and Company Performance}

\section{Sandra Schillo}

Table 1. Measuring the components of entrepreneurial orientation

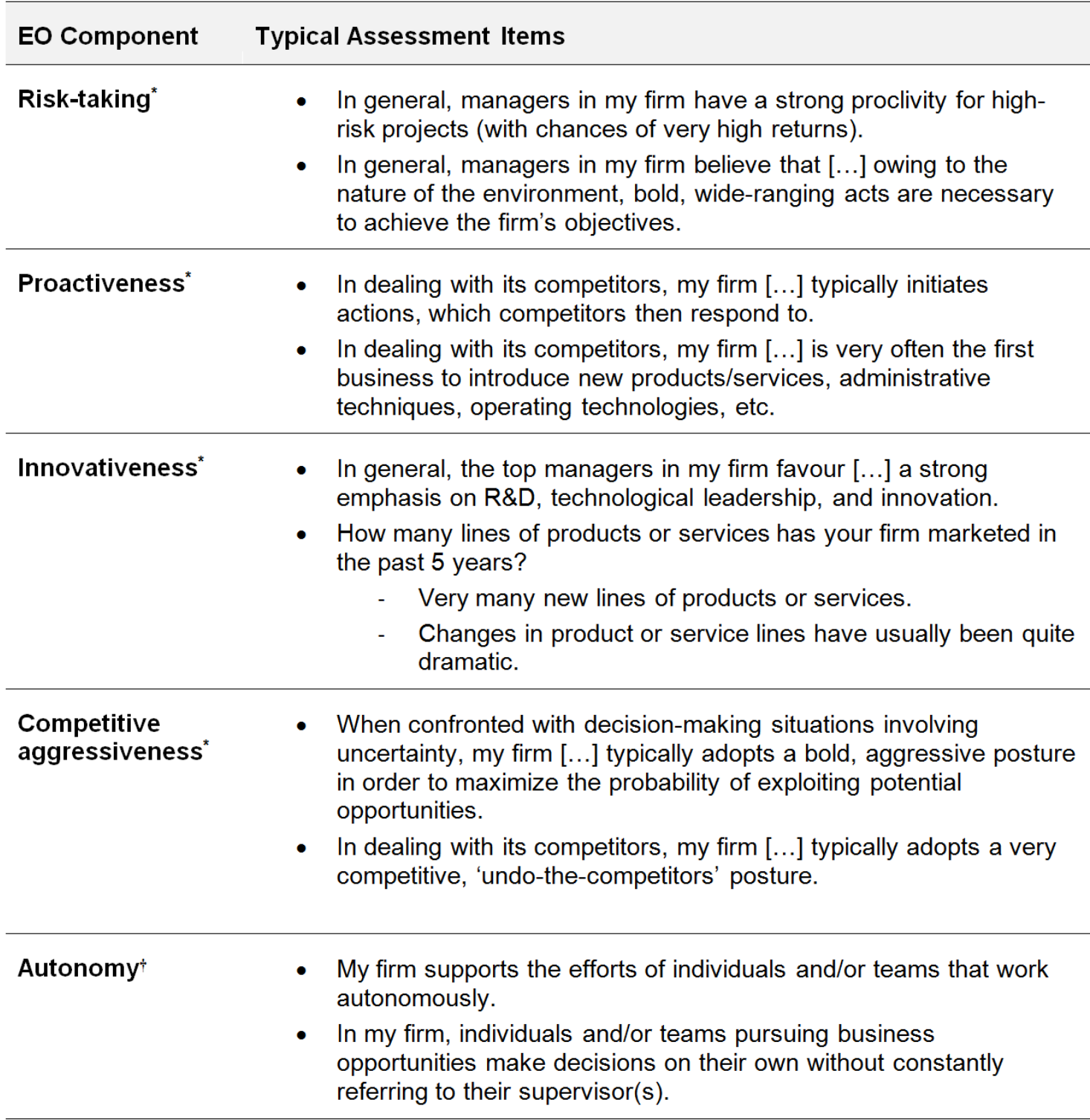

*Example statements are selected from Covin and Slevin (1989; http://tinyurl.com/6drqgjk).

†Example statements are selected from Lumpkin, Cogliser, and Schneider (2009; http://tinyurl.com/63p6gat).

approach implies that the different components covary with each other. Indeed, some empirical studies document high correlations or respective results from factor analyses and can reasonably take such an approach (Covin and Slevin, 1989). Other studies, however, report lower correlations or weaker factor analysis results between the components (Ferreira et al., 2011; http://tinyurl.com/4xeoobz). From a management perspective, it would be important to know under which circum- stances companies can expect risk-taking, proactiveness, innovativeness, competitive aggressiveness, and autonomy to correlate.

Other authors suggest that the dimensions may vary independently. EO is then constructed as the sum of scores across the separate dimensions or similarly as a weighted linear combination. From a management perspective, this would imply that companies can make up 


\section{Entrepreneurial Orientation and Company Performance}

\section{Sandra Schillo}

for a lower score on proactiveness, for example, by being more innovative. Where EO has been found to increase success, this would mean that increases on any one component would help companies become more successful.

While these two approaches can be implemented relatively easily with current statistical methodologies (Diamantopoulos and Winklhofer, 2001; http://tinyurl.com /3rujecm), it seems that neither is likely to reflect managers' experience in all cases. Indeed, the purpose of the original work relating to EO in this tradition (Miller, 1983) was to "show the merits of a configurational approach to the study of organizations" (Wiklund and Shepherd, 2011; http://tinyurl.com/3gzgvqh): Miller used the example of entrepreneurship to show that EO has different drivers and different manifestations in different types of companies. Work following a similar approach would clearly improve the applicability of EO to specific management contexts.

However, much of the later work has instead treated the EO scale with the three or five dimensions defined above (i.e., risk-taking, proactiveness, and innovativeness, with or without competitive aggressiveness and autonomy) as a universally relevant construct and has focused on the relationship between EO and firm performance and the various moderating influences on this relationship. This work has led to an extensive list of publications: at least 134 relevant studies prior to 2007 (Rauch et al., 2009; http://tinyurl.com/3kjbwfr) and another 67 publications between 2006 and 2009 (Miller, 2011).

Studies in this tradition have identified a broad range of factors that influence how EO relates to company performance, the most important of which are outlined in the following section.

\section{Management Implications of the Results of Prior Research}

At first sight, the academic literature seems to lead to the conclusion that higher EO leads to increased performance. This finding can be derived from many published studies, as well as a meta-analysis (Rauch et al., 2009), which suggests that the correlation between EO and performance is significant, although only moderately strong. Upon further investigation, it becomes clear very quickly that the relationship between EO and performance is not a straightforward, positive relationship. There are three key considerations that may be of critical importance to managers aiming to optimize the performance of their company:

1. The existence of moderators in the relationship. The meta-analysis quoted above (Rauch et al., 2009) also emphasizes that the positive relationship between EO and performance does not hold homogeneously for all contexts. Rather, there are likely moderators that will determine how EO affects performance. Based on the data available for the meta-analysis, the authors identify the following moderators, all of which only show moderately large correlations with performance:

- Company size: EO was significantly more important to company performance for micro businesses than for small businesses. Large companies scored in between these two groups, but the difference was not statistically significant. The results for company size also suggest that there are additional moderators.

- Industry: EO was significantly more important for high-tech industries than non-high-tech industries.

- Culture: Using continents as proxies for culture, the authors do not find significant differences.

Given the inherent constraints in meta-analyses, these results are limited to a small number of potential moderators that could be coded consistently across the literature and that could be derived from theory. A review of the vast literature reveals many more potential moderators, some of which are: dynamics of the environment, munificence, complexity, and various organizational factors (see Lumpkin and Dess, 1996). Typically, researchers analyze the impact of one of these factors at a time in combination with EO.

From a management perspective, this research approach is quite problematic. Any company finds itself in a context characterized by all of these factors. Its environment will display a certain dynamism, the company will have access to a certain level of resources, and its industry will be characterized by a certain level of complexity. Separate analyses of each of these dimensions can only lead to very limited recommendations regarding the entrepreneurial orientation of a company.

2. The potential that the EO-performance relationship may be curvilinear. EO has been found to have a curvilinear relationship with performance in a number of studies, implying that the positive impact of EO levels 


\section{Entrepreneurial Orientation and Company Performance}

\section{Sandra Schillo}

off or even becomes negative beyond a certain threshold. Other studies report specifically testing for the curvilinear relationship and not finding a significant impact. These differences suggest that there may be moderators that cap the positive impact of EO at a certain level or that certain populations of companies do not usually reach the level of EO at which it becomes less effective.

From a management perspective, these findings may be useful even though it is going to be important to identify the source of the difference in these findings. For the time being, the findings spell a warning that here is the possibility of a company becoming "too entrepreneurial". Ideally, managers would need to know under which circumstances this occurs or among which type of company this is likely to occur.

\section{The potential that the nature of academic publish-} ing introduces biases in the types of results reported. The common practice of academic journals is to favour the publication of studies with strong, statistically significant findings over those that report non-significant findings. For examples of this bias across disciplines, see Csada et al., 1996; http://tinyurl.com/3w2rtdl. It is plausible to assume that there may be a number of studies that found a non-significant impact of EO on performance, and that these studies may not have been published as a consequence.

There is a reason to assume that this scenario is quite likely: studies that report findings for individual components of the EO construct often only report on two or three components. It seems rather unlikely that at least some authors would not have also included the additional 4-6 items of the entire EO scale in their study design. The fact that only a subset is reported on perhaps suggests that the findings were not significant and thus not useful for publication. Considering common publication practices, it thus seems quite likely that studies like the meta-analysis by Rauch et al. (2009) quoted above overestimate the positive impact of EO.

\section{Conclusions and Suggestions for Future Re- search}

The concept of EO has proven fruitful in sparking a substantive body of academic research. It is remarkable in the context of entrepreneurship research in that it has been defined relatively consistently across a large number of studies. Although there are issues related to the definition and related measurement approaches, metaanalytical research provides some evidence that the overall findings are relatively robust. Thus, from an academic perspective the question arises whether the literature is "at a point of saturation with little more to learn, or can future investigations of EO still make contributions to the strategy and/or entrepreneurship literature?" (Wiklund and Shepherd, 2011)

From a management perspective, the discussion presented above suggests that much remains to be learned before the existing insights can reliably be translated into management recommendations. There are some useful pointers. For example, the finding that entrepreneurial orientation often has a curvilinear effect on performance spells a useful warning for managers.

Beyond this finding, the literature can only provide limited guidance for managers of individual companies. While it is interesting to know that, in general, EO may contribute positively to performance, each business faces very specific combinations of external influences and internal corporate characteristics. These combinations are not typically dominated by the two or three factors that individual studies on EO have investigated. Rather, managers need specific guidance under what combination of external and difficult-to-alter internal circumstances an increased EO can lead to increased performance. Thus, while there is a relatively substantial body of literature on EO, academic research would need to deliver much more specific results in order to provide reliable guidance for management.

This requirement is likely to provide a substantial challenge for academic research. Current methodologies using regression analyses typically can only provide reliable findings for a small number of variables, and even the use of structural equation models is limited by the number of items any questionnaire can realistically contain. To date, this challenge has not been systematically addressed in the business literature. Potentially, research from decision science or the broader area of computer science might lead to useful approaches to integrate the findings from existing studies or to more advanced study designs.

Progress in this area is also hampered by the lack of consistent testing for reliability and especially for the validity of EO scales used (Lyon, Lumpkin, and Dess, 2000; http://tinyurl.com/6f4drn7). As noted above, the EO 


\section{Entrepreneurial Orientation and Company Performance}

\section{Sandra Schillo}

scale is one of the more heavily researched concepts in entrepreneurship research, and it can be expected that the reliability and validity of other, less popular, scales may also be insufficient to provide a strong basis for management interventions. On a positive note, current statistical methodologies provide the tools to establish reliability and validity, and researchers and editors are well positioned to deliver published work that meets the needs of management applications.

\section{About the Author}

Sandra Schillo is a researcher and consultant in the area of innovation and entrepreneurship. She is the Founding Editor of Innovation \& Entrepreneurship (www.innovationentrepreneurship.com), a publication founded to make academic literature on innovation and entrepreneurship accessible to policy professionals and researchers. She also is the President of Innovation Impact Inc. (www.innovation -impact.com), a company specializing in custom research and consulting services in the areas of innovation, science and technology policy, and entrepreneurship. Dr. Schillo is also on the Review Board of the Technology Innovation Management Review.

Dr. Schillo obtained her Doctorate from the Institute for Entrepreneurship and Innovation Management, University of Kiel, Germany, and received her Masters' degree in Industrial Engineering from the University of Karlsruhe, Germany. She has extensive experience working with government departments and agencies on innovation and entrepreneurship. Dr. Schillo draws on both her practical and academic experience to ensure the relevance and quality of her work. 